\title{
Introduction: mental capacity and value neutrality
}

\author{
Jillian Craigie \\ University College London
}

Legal structures that stipulate when a person no longer has the right to make certain decisions for themselves often assign the concept of mental capacity a central role. In jurisdictions where this is the case, the concept of mental capacity is one of the main tools available to medical and care professionals and courts, to help them navigate the often difficult and contested path between unjustified paternalism and neglect. Understand the concept too broadly, or apply it too stringently, and this will result in inappropriate infringements on personal liberty. However, an overly narrow conception, or undemanding application of the concept in practice, will result in failures to care appropriately for some who need the state to intervene in their private affairs.

An assumption often in the background of debates about mental capacity is that infringements by the state on personal freedoms in relation to private decisions are justified only when the individual's ability to decide autonomously is relevantly impaired. However, the relationship between being autonomous and having mental capacity in the legal sense is often unclear in the literature. The nature of this relationship is one of the themes explored throughout the articles in this special issue. In addition to freedom from certain kinds of interference from others, being autonomous is generally thought to require certain psychological capacities, and it is this element that is linked to the concept of mental capacity. Genevra Richardson writes that mental capacity is the 'legal expression' of autonomy in this sense (p. 9I).

One of the difficult questions in this area of law is how to decide which psychological incapacities should be taken into account in assessments of mental capacity. In the context of debates about what grounds properly distinguish non-autonomous from autonomous decisions, or incapacity from capacity, one widely endorsed view holds that the grounds used to draw these lines are appropriate only if they are value neutral. Other factors will be in the mix because not all valueneutral considerations will be appropriate for inclusion as a requirement for autonomy or capacity, but on such views value neutrality is a necessary feature.

A political commitment to value neutrality limits - in one way or another - the substantive considerations that can be brought to bear on questions of autonomy or capacity, with the aim of being inclusive when it comes to the different kinds of life people choose to live. The motivating concern is that the requirements necessary for autonomy or capacity should be minimal, particularly in the sense that they leave wide open the issue of what life-shaping commitments those with autonomy or capacity can have. Proponents hold that law and public policy in liberal states should be value neutral. This special issue addresses questions that arise when this principle is applied to law relating to mental capacity, with a focus on decisions about medical treatment.

One question concerns how limited the requirements must be for a capacity test to count as value neutral. My contribution to the special issue addresses one dimension of this question, by exploring whether conceiving of mental capacity in diachronic terms - as extended over time - would be consistent with a value-neutral approach. It is concluded that 'considerations derived from a diachronic perspective are relevant to questions of treatment decision-making liberty - especially 
in the context of mental disorders - but that they are difficult to reconcile with a value-neutral approach to identifying incapacity', which I suggest presents us with a moral bind (p. 5).

In their article, Tony Hope and colleagues use first person reports from people with anorexia nervosa to tease apart various ways that autonomy can be compromised in this disorder. In doing so, they call into question the sharp distinction drawn between preferences and beliefs, which is used to rule out certain considerations from assessments of mental capacity on the grounds that they concern matters of value. The four problems they identify are: (i) 'problems with agency'; (ii) 'affective components, particularly anxiety, can dominate beliefs such that the grounds for making a decision may differ from the reasons given in justification'; (iii) 'the interactions between the affective components and the objective evidence lead to substantial inner conflicts with resulting lack of stability in preferences and beliefs'; and (iv) 'this lack of stability leads to concerns around identity and authenticity' (p. 2I). Hope and colleagues argue that only some of these problems should be taken into account in questions regarding involuntary treatment, therefore proposing an asymmetry between mental capacity and the psychological capacities necessary for autonomy. They conclude, however, that 'there is a significant group of people who could be assessed as competent [on the basis of current tests for capacity] but whose refusal of treatment ... may not be autonomous [in ways relevant to capacity]' (p. 34).

Another question concerns whether current legal definitions of incapacity are value neutral. The contribution by Catriona Mackenzie and Wendy Rogers analyses the conception of capacity in the Mental Capacity Act 2005 (MCA) in England and Wales. They argue that while the Act's definition of incapacity in terms of a procedural test seems to understand the concept in primarily cognitive and value-neutral terms, an adequate application of its guiding principles and Code of Practice requires a much richer understanding of capacity and incapacity. In particular, Mackenzie and Rogers argue that the Code's interpretation of the MCA's guiding principles appeals to conditions of authenticity and diachronic coherence, and that establishing these involves engagement in a dialogical process. Their analysis suggests that social dimensions of autonomy play a central role in the MCA's approach to understanding and identifying capacity and incapacity.

A number of articles in this special issue address the question of whether value neutrality is something that legislators and courts should aim for. Mackenzie and Rogers argue that rather than raising the bar for capacity too high, the substantive requirements that they focus on could enable vulnerable persons to achieve the greatest degree of autonomy possible for them. In their article, Fabian Freyenhagen and Tom O'Shea 'highlight significant shortcomings in purportedly normatively neutral accounts of mental capacity, shown by their inability to identify the capacitysubverting, and so autonomy-undermining, effects of some mental disorders' (p. 54). They call for recognition that mental capacity tests must have substantive elements in order to fulfil their legal role. Given this, they recommend alternative measures to guard against unjustified paternalism: increased transparency, democratic contestability, and historically sensitive caution against involuntary detention and treatment.

In her article, Natalie Banner argues that the adoption of procedural tests for incapacity in the pursuit of value neutrality results in a legal fiction because the "procedural elements of decisionmaking [cannot] in principle be considered separately from the substantive contents of beliefs and values that inform the decision outcome' (p. 7I). She prescribes instead that the law should adopt a compromise approach according to which mental capacity is understood in terms of having 'recognisable reasons'. Banner argues that the proposed approach is not value neutral, because it acknowledges 'the interplay between procedural and substantive elements of decision-making' (p. 7I), but that it nonetheless avoids unwarranted paternalism.

Genevra Richardson's article grapples with the idea that, 'If persons without disabilities are permitted to refuse life-saving treatment, then persons with disabilities, including mental disabilities, must be equally permitted to do so' (p. 93). She considers how this principle might be 
upheld in English law using the concepts of mental capacity, best interests and mental disorder, with a focus on whether a shift to supported decision-making in line with the UN Convention on the Rights of Persons with Disabilities might offer a better solution. Ultimately, she wonders whether in the pursuit of neutrality we might risk 'losing the hard-won advances achieved under other established international human rights principles' (p. го3).

This special issue came about as the result of a workshop run at the University of Melbourne with the generous support of the University of Melbourne's Social Justice Initiative. Thanks go to all those who attended, and special thanks go to Alicia Coram who was the co-organizer of the event. This work was done with the support of the Wellcome Trust [0949io]. 